\title{
EXPERIMENTAL AND FIRST PRINCIPLES STUDY OF STRUCTURAL, ELECTRONIC AND OPTICAL PROPERTIES OF $\mathrm{ZN}_{0.875} \mathrm{MN}_{0.125} \mathrm{O}$ THIN FILM
}

\author{
BAHRI DEGHFEL ${ }^{1}$, ABDELHAFID MAHROUG $^{2}$, RABIE AMARI $^{2}$, AMMAR BOUKHARI $^{2}$, \\ ABDELOUHAB BENTABET ${ }^{3}$ \\ ${ }^{1}$ University of Mohamed BOUDIAF, Laboratory of Materials Physics and its Applications, \\ Faculty of Sciences, Physics Department,28000 M'sila, Algeria, badeghfel@gmail.com \\ ${ }^{2}$ University of Mohamed Boudiaf, Faculty of Technology, Mechanical Engineering Department, \\ 28000,Algeria,hafidmahroug@yahoo.fr,a.lamari28@gmail.com,ammar.boukhari@gmail.com \\ ${ }^{3}$ University of Mohamed El Bachir El Ibrahimi, Laboratory of characterization and valuation of \\ natural resources, Bordj-Bou-Arreridj 34030,Algeria, a.bentabet@gmail.com
}

\begin{abstract}
$\mathrm{Zn}_{0.875} \mathrm{Mn}_{0.125} \mathrm{O}$ thin films are fabricated by a simple sol-gel spin-coating technique on glass substrates using zinc acetate dehydrate $[\mathrm{Zn}(\mathrm{CH} 3 \mathrm{COO}) 2 \cdot 2 \mathrm{H} 2 \mathrm{O}]$ and manganese acetate tetrahydrate $\left[\mathrm{Mn}\left(\mathrm{CH}_{3} \mathrm{COO}\right)_{2} 4 \mathrm{H}_{2} \mathrm{O}\right]$ as a starting material and doping source. Isopropanol and monoethanolamine (MEA) were used as solvent and stabilizer, respectively. X-ray diffraction, ultraviolet-visible spectroscopy and photoluminescence spectroscopy are employed to investigate the effect of $\mathrm{Mn}$ doping on the structural, electronic and optical properties of $\mathrm{ZnO}$ thin films. The obtained results are compared with those using first-principles calculation based on density functional theory (DFT) with local density approximation (LDA) plus Hubbard U (DFT-LDA+U) method. This latter represents the theoretical framework to deal with strongly correlated materials to predicted successfully the electronic properties of such materials.
\end{abstract}

Keywords: Sol-gel spin-coating technique, Mn-doped ZnO thin film, DFT.

\section{INTRODUCTION}

$\mathrm{ZnO}$ is a wide band-gap $(3.37 \mathrm{eV})$ compound semiconductor that have received considerable attention (Yaakob et al., 2014; Ozgur et al., 2005). The Mn ferromagnetic element is widely used in doping II-IV-based hosts, like Mn-ZnO (Luo et al., 2005; Zhao et al., 2010). Previous studies (Luo et al., 2005; Zhao et al., 2010; Zhao et al., 2012) have found that the $\mathrm{Mn}-\mathrm{Mn}$ interaction is dominated by antiferromagnetic (AFM) coupling. The doping of $\mathrm{ZnO}$ thin films by $\mathrm{Mn}$ element presents a feasible means to adjust the band gap. The tuning of the band gap allows DMS to be used as UV detectors and light emitters.

The first-principles and pseudopotentials method based on conventional density functional theory (DFT) cannot efficiently describe the localization of strongly correlated $d$ and $f$ electrons of transition material (Anisimov et al., 1997; Dudarev et al., 1998). The DFT-LDA+U approach (Yaakob et al., 2014; Anisimov et al., 1997) can significantly improve the calculation including transition metal localization.

Variety of techniques have been used to prepare $\mathrm{ZnO}$ thin films. Because of its simplicity, low cost, safety, large area deposition, controllability of compositions and uniformity of thickness, the sol-gel method has attracted much attention (Amari et al., 2018; Mahroug et al., 2017).

The aim of this study is to investigate experimentally and theoretically by using first-principles calculations, the structural, electronic and optical properties of $\mathrm{Zn}_{0.875} \mathrm{Mn}_{0.125} \mathrm{O}$ Thin film. 


\section{EXPERIMENTAL AND THEORETICAL DETAILS}

Sol-gel spin coating method was used to prepare $\mathrm{Mn}$-doped $\mathrm{ZnO}$ thin films on glass substrate. Zinc acetate dihydrate $\left[\mathrm{Zn}\left(\mathrm{CH}_{3} \mathrm{COO}\right)_{2} .2 \mathrm{H}_{2} \mathrm{O}\right]$ and manganese acetate tetrahydrate $\left[\mathrm{Mn}\left(\mathrm{CH}_{3} \mathrm{COO}\right)_{2} \cdot 4 \mathrm{H}_{2} \mathrm{O}\right]$ were used as a starting material and dopant source, respectively, and the isopropanol was added as stabilizer. The molar ratio of the solvent (monoethanolamine; MEA) to metal ions was fixed at 1.0 and the concentration of metal ions was $0.7 \mathrm{M}$. The $\mathrm{Mn}$ dopant concentration was chosen as $12.5 \mathrm{~mol} \%$. The subsequent steps were discussed in our previous works (Amari et al., 2018; Mahroug et al., 2017).

An X-ray diffractometer (XRD) (Bruker 8 Advance; $\lambda=1.5406 \mathrm{~A}^{\circ}$ ), UV-vis spectrophotometer (UV-3101 PC-Shimadzu) and spectrofluorimeter (Perkin Elmer LS 50B; excitation source at $325 \mathrm{~nm}$ ), was used to characterize the structural properties, the optical transmission spectra and the photoluminescence (PL) of the $\mathrm{ZnO}$ thin films, respectively.

First-principles calculations of structural, electronic and optical properties of Mndoped $\mathrm{ZnO}$ material $\left(\mathrm{Zn}_{1-x} \mathrm{Mn}_{x} \mathrm{O} \mathrm{x}=12.5 \%\right)$ with wurtzite structure were performed using DFT as implemented in CASTEP code (Clark et al., 2005). The 2.2.2 ZnO supercell containing 32 atoms is used and the substitutional method is adopted (Zhao et al., 2012) to achieve this concentration in which two $\mathrm{Zn}$ atoms are substituted by $\mathrm{Mn}$ and different geometry configurations for $\mathrm{Mn}$ atoms were taken. The exchangecorrelation function is treated by the generalized gradient approximation (GGA) in the scheme of Perdew-Burke-Ernzerhof (PBE) (Perdew et al., 1996). Also, the valenceelectron configurations for the oxygen, zinc and manganese atoms are employed as $2 \mathrm{~s}^{2}$ $2 p^{4}, 3 d^{10} 4 s^{2}$ and $3 d^{5} 4 s^{2}$, respectively. The cut-off kinetic-energy of $450 \mathrm{eV}$ was used. The 7.7.4 k-point grid was adopted over the first Brillouin zone sampling mesh. The optimization convergence for energy change, maximum force, maximum stress, and maximum displacement were set at $5 \times 10^{-6} \mathrm{eV} /$ atom, $0.01 \mathrm{eV} / \AA, 0.02 \mathrm{GPa}$, and $5.0 \times$ $10-4 \AA$, respectively. Furthermore, the SCF convergence threshold is fixed at $5.010^{-7}$ $\mathrm{eV}$ per atom. The semiempirical LDA+U approach (Anisimov et al., 1997) with effective Hubbard $\mathrm{U}$ values of $7 \mathrm{eV}$ to treat the transition metal of $\mathrm{Zn} 3 d$ and $M n 3 d$ electrons was employed.

\section{RESULTS}

The total energies of the five different geometry configurations for substitution of Zn by Mn, marked as A: $\mathrm{Pm}\left(C_{s}^{1}\right), \mathrm{B}: \mathrm{Cm}\left(C_{s}^{3}\right), \mathrm{C}: \mathrm{P} 3 \mathrm{~m} 1\left(C_{3 v}^{1}\right), \mathrm{D}: \mathrm{P} 3 \mathrm{~m} 1\left(C_{3 v}^{1}\right)$ and $\mathrm{E}:$ $\mathrm{Cm}\left(C_{s}^{3}\right)$, are presented in Table 1 .

Table 1. Total energy for different geometry configurations. Energy corresponds to configuration $\mathrm{A}$ is chosen as an energy reference

\begin{tabular}{lc}
\hline Configuration & $\mathrm{E}(\mathrm{eV})$ \\
\hline $\mathrm{A}$ & 0 \\
$\mathrm{~B}$ & $-0,978$ \\
$\mathrm{C}$ & $-0,0249$ \\
$\mathrm{D}$ & $-0,0433$ \\
$\mathrm{E}$ & 0,0085 \\
\hline
\end{tabular}


Total energy in configuration A was chosen as an energy reference. It is clear from the figure that the ground state is found to be the configuration $\mathrm{B}$ corresponding to symmetry group $\mathrm{Cm}\left(C_{s}^{3}\right)$. So, this configuration will be considered for Mn-doped $\mathrm{ZnO}$ material with $x=12,5 \%$.

The optimized lattice constant along c-axis is found to be around $5.34 \mathrm{~A}^{\circ}$ which is slightly underestimated by around $2 \%$ by our experimental result $\left(5.23 \mathrm{~A}^{\circ}\right)$ extracted from XRD pattern (figure 2). The (002) diffraction peak is stronger than the other peaks, indicating a preferential growth direction along the c-axis due to its lowest surface free energy among (002) planes.

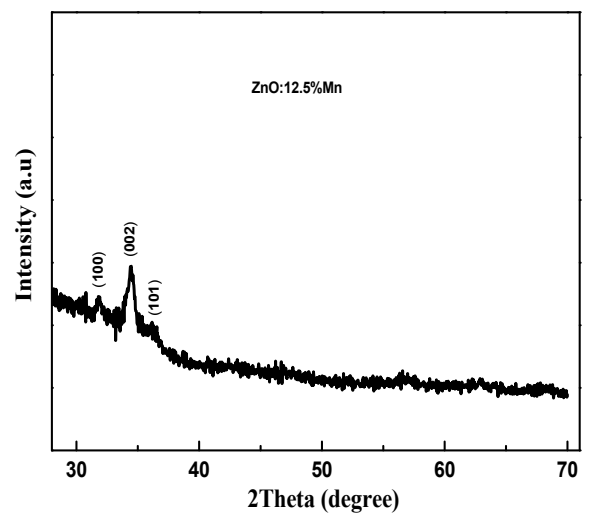

Figure 2. XRD pattern of $\mathrm{Zn}_{1-\mathrm{x}} \mathrm{Mn}_{\mathrm{x}} \mathrm{O}(\mathrm{x}=12.5 \%)$ thin film

The optical transmission spectra at room temperature of $\mathrm{Zn}_{1-\mathrm{x}} \mathrm{Mn}_{\mathrm{x}} \mathrm{O}(\mathrm{x}=12.5 \%)$ thin films is shown in figure 3. It revealed that the sample is transparent in the visible optical region with an average transmittance about of $62 \%$.

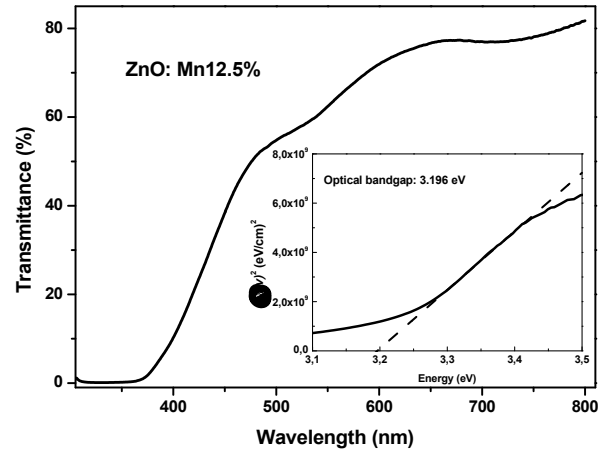

Figure 3. Optical transmission spectra of $\mathrm{Zn}_{1-\mathrm{x}} \mathrm{Mn}_{\mathrm{x}} \mathrm{O}(\mathrm{x}=12.5 \%)$ thin film. Inset presents a plot of $(\alpha h v)^{2}$ vs. photon energy (hv)

The absorption coefficient $\alpha$ is related to the optical band gap energy Eg as: 
$\alpha h v=$ constant $(h v \quad E g)$

The absorption coefficient $\alpha$ can be calculated by the equation

$\alpha=\frac{1}{t} \ln \left(\frac{1}{T}\right)$

where $T$ is the transmittance index and $\mathrm{t}$ is the film thickness. The Eg value is therefore determined by extrapolating the linear portion of the plot relating $(\alpha h v)^{2}$ versus $h v$ (inset in figure 3 ).

The obtained value of $\mathrm{Eg}$ is $3.196 \mathrm{eV}$. which is highly underestimated by the theoretical value obtained here $(0.91 \mathrm{eV})$. It is well known that the conventional DFT can underestimate the experimental band gap and despite the incorporation of the semiempirical LDA $+\mathrm{U}$ approach, there is still a significant gap between experience and theory.

\section{CONCLUSION}

Structural, electronic and optical properties of $\mathrm{Zn}_{0.875} \mathrm{Mn}_{0.125} \mathrm{O}$ thin films are investigated experimentally and theoretically, within the framework of DFT. The optimized lattice constant is found in a good agreement with the experimental one extracted from XRD pattern. This latter revealed that the preferential growth direction was along the c-axis. The fabricated thin film was transparent in the visible optical region with an average transmittance about of $62 \%$. The deduced experimental band gap was found underestimated by the theoretical one.

\section{REFERENCES}

Amari, R. et al. (2018), "Structural, Optical and Luminescence Properties of ZnO Thin Films Prepared by Sol-Gel Spin-Coating Method: Effect of Precursor Concentration”, Chinese Physics Letter, 35, 016801, https://doi.org/10.1088/0256-307X/35/1/016801.

Anisimov, V.I., Aryasetiawan, F. and Lichtenstein, A.I. (1997), "First-principles calculations of the electronic structure and spectra of strongly correlated systems: the LDA+U method", Journal of Physics: Condensed Matter, 9, 767-808, https://doi.org/10.1088/0953-8984/9/4/002.

Clark, S.J. et al. (2005), "First principles methods using CASTEP", Zeitschrift für Kristallographie, 220, $567-$ 70, https://doi.org/10.1524/zkri.220.5.567.65075.

Dudarev, S.L. et al. (1998), "Electron-energyloss spectra and the structural stability of nickel oxide: An LSDA+U study", Physical Review B, 57, 1505, https://doi.org/10.1103/PhysRevB.57.1505.

Luo, J. et al. (2005), "Structure and magnetic properties of Mn-doped ZnO nanoparticles", Journal of Applied Physics, 97, 086106, https://doi.org/10.1063/1.1873058.

Mahroug, A. et al. (2017), "Synthesis, Structural, Morphological, Electronic, Optical and Luminescence Properties of Pure and Manganese-Doped Zinc Oxide Nanostructured Thin Films: Effect of Doping", Journal of Nanoelectronics and Optoelectronics, 12, 1-10, https://doi.org/10.1166/jno.2018.2271.

Ozgur, U. et al. (2005), "A comprehensive review of $\mathrm{ZnO}$ materials and devices", Journal of Applied Physics, 98, 041301, https://doi.org/10.1063/1.1992666.

Perdew, J.P., Burke, K. and Ernzerhof, M. (1996), "Generalized Gradient Approximation Made Simple", Physical Review Letters, 77, 3865, https://doi.org/10.1103/PhysRevLett.77.3865.

Yaakob, M.K. et al. (2014), "First Principles LDA+U Calculations for ZnO Materials", Integrated Ferroelectrics, 155, 15-22, https://doi.org/10.1080/10584587.2014.905086.

Zhao, L. et al. (2010), "The electronic and magnetic properties of (Mn, N)-codoped $\mathrm{ZnO}$ from first principles", Journal of Applied Physics, 108, 113924, https://doi.org/10.1063/1.3511365.

Zhao, L. et al. (2012), "The electronic and magnetic properties of (Mn,C)-codoped $\mathrm{ZnO}$ diluted magnetic semiconductor", Chinese Physics B, 21, 097103, https://doi.org/10.1088/1674-1056/21/9/097103. 